\title{
Economic Freedom, Internal Motivation, and Corporate Environmental Responsibility of SMEs
}

\author{
Johan Graafland ${ }^{1}\left(\mathbb{D} \cdot\right.$ Reyer Gerlagh $^{2}$
}

Accepted: 20 July 2019 / Published online: 9 August 2019

(c) The Author(s) 2019

\begin{abstract}
The effect of economic freedom on firms' environmental responsible management is still unconcluded. We conjecture that the effects are conditional on a firm's internal motivation and use a large-scale survey to run an empirical test. The sample consists of 4338 small and medium-sized enterprises from twelve European countries. Distinguishing between intrinsic (environmental) and extrinsic (profit) internal motivations, we find clear support that the effects of economic freedom and intrinsic motivation on corporate environmental performance interact with each other. Our findings explain the ambiguous results of previous empirical studies at the aggregate level.
\end{abstract}

Keywords Corporate environmental performance $\cdot$ Economic freedom $\cdot$ Intrinsic motivation $\cdot$ Extrinsic motivation $\cdot$ Interaction

\section{Introduction}

Whether free-market capitalism is compatible with or harmful to environmental sustainability is strongly debated. Various authors argue that capitalism may inhibit corporate environmental performance, because private industry will invest in the most profitable technologies, which leads to a focus on the cheapest rather than environmentally responsible processes (Williamson et al. 2006; Bell 2015). Other authors argue that economic freedom in markets and competition stimulate corporate environmental performance (CEP) (Baughn et al. 2007; Jackson and Apostolakou 2010; Kinderman 2012; Hartmann and Uhlenbruck 2015), and businesses has expressed its interest in adopting a more extensive CEP approach conditional upon receiving greater freedom from the state (Kinderman 2008).

Johan Graafland

J.J.Graafland@uvt.nl

Reyer Gerlagh

r.gerlagh@tilburguniversity.edu

1 Department of Economics, Tilburg Sustainability Center/CentER, Tilburg University, Room P1205, Warandelaan 2, 5000 LE Tilburg, The Netherlands

2 Department of Economics, Tilburg Sustainability Center/CentER, Tilburg University, Room P1210, Warandelaan 2, 5000 LE Tilburg, The Netherlands 
While others have considered the benefits and costs of regulation (cf. Brammer et al. 2012; Agan et al. 2013); we look at the broad measure of economic freedom. Economic freedom means that property rights are secure and that individuals are free to use, exchange, or give their property to another as long as their actions do not violate the identical rights of others (Gwartney and Lawson 2003). Economic freedom declines if the government intervenes through taxation, trade tariffs or other trade barriers, or regulations of credit, output and labor markets. A stronger protection of property rights has been found to lead to environmental improvements (Ioannou and Serafeim 2012). Free trade, another exponent of economic freedom, has however, ambiguous effects. Whereas the so-called gains-from-trade hypothesis presumes that trade has a positive effect on the environment; the so-called race-to-the-bottom hypothesis states that open countries adopt lax environmental standards and become pollution havens in order to attract multinational corporations or export pollution-intensive goods (Frankel and Rose 2005). A literature study of Carson (2010) shows that the supporting empirical evidence of either hypothesis remains scant and fragile. Also for state regulation, evidence is mixed. Camisón (2010) found that the effectiveness of coercive regulation in promoting environmental innovation is lower than voluntary policies. Demirel et al. (2018) found that effective environmental protection entails collaboration between government regulation and voluntary environmental measures. Coercive legislation does not leave much room for flexibility and voluntary choices by managers and frequently pushes the manager to adopt environmental measures without considering effectiveness (Daddi et al. 2016). For economic freedom more generally, Jackson and Apostolakou (2010) argue and found that firms in liberal market economies outstrip firms in coordinated market economies, because their voluntary CEP initiatives substitute for the lack of government interventions. Kinderman (2012) stated that during the period of rapid deregulation and liberalization in the UK (a typical liberal market economy) CEP not only developed and thrived, but even managed to outperform the previous economic model in terms of corporate accountability and corporate standards.

We contribute to this literature, presenting evidence for an important modification of the argument of Jackson and Apostolakou (2010) and Kinderman (2012) that companies voluntarily adopt a more extensive CEP approach if the state reduces its interventions: the positive effect of economic freedom on CEP is conditional on internal motivations to CEP. The literature on motives for corporate social performance (CSP) (which includes corporate environmental performance) distinguishes between extrinsic and intrinsic motives (Muller and Kolk 2010). ${ }^{1}$ An extrinsic motive encourages CEP if it is instrumental for other goals, such as financial performance or the company's reputation. Intrinsic motives perceive CEP as an end in itself, independent from other benefits. Intrinsic (environmental) motivation may stem from personal satisfaction of engaging in CEP when executives enjoy helping others or from a sense of responsibility to contribute to society and the welfare of future generations (Lindenberg 2001). Previous studies have focused on drivers external and internal to the firm (Weaver et al. 1999; Aguilera et al. 2007; Bracke et al. 2008; Haller and Murphy 2012), but did not consider that the influence of internal drivers interact with the external drivers. We fill a gap in this literature studying this interaction, exploiting the variation between companies in their environmental motivation and between countries in their level of economic freedom. We hypothesize and test that economic freedom increases CEP for firms with internally motivated managers, e.g. through voluntary actions (Alberini and Segerson 2002), while absence of economic freedom increases CEP for firms without.

${ }^{1}$ See Pellerano et al. (2017) for a similar distinction at the consumer side. 


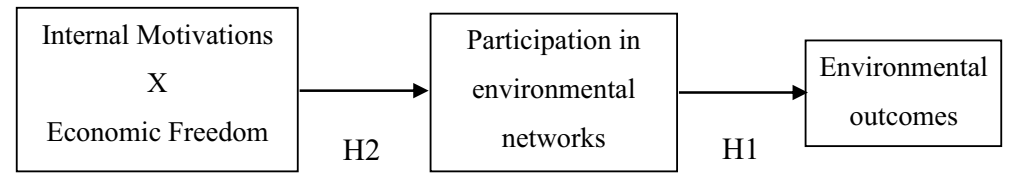

Fig. 1 Conceptual model

Our paper thereby fits in a growing literature that considers more 'behavioral' drivers for environmental performance (Croson and Treich 2014).

We focus on small and medium sized enterprises (SMEs), as the managers' values and motives play a relatively important role for these (Revell et al. 2010). We use a recent survey with entries for 4338 companies from 12 European countries; we interact managerial motivation with country economic freedom to test its effect on environmental performance. The use of survey data allows us a deeper look into motivation, complementing previous studies that focus on public structural data (cf. Bracke et al. 2008; Haller and Murphy 2012).

Our paper thus makes two major contributions to existing literature. First, we extend and deepen existing literature on institutional drivers of CEP by arguing that the impacts of market institutions on CEP depend on their virtuous interaction with internal motivations towards CEP. Second, we test empirically if and what kind of motivation interacts with economic freedom in their influences on CEP. We exploit a sample of SMEs from 12 European countries that provides a good setting for such a study because of the prominence of manager's personal motivations in CEP strategies of SMEs.

\section{Hypotheses}

Corporate environmental performance is one of the dimensions of the broader concept of corporate social performance. Wood defines corporate social performance as "a business organization's configuration of principles of social responsibility, processes of social responsiveness, and policies, programs and observable outcomes as they relate to the firm's societal relationships" (Wood 1991: 693). Wood's definition consists of three parts (Wood 2010). The first part concerns the principles of social responsibility and constitutes the motivations for companies to be involved in CEP. The second part refers to the processes of CEP, including stakeholder management and environmental policies. The third part comprises the outcomes in terms of the effects on stakeholders and society, including the effects on the natural environment. In our empirical analysis, we measure internal motivations to CEP that link to the first part of Wood's definition. We also measure the implementation of environmental policies and their outcomes, linking to the second and third parts of corporate environmental performance.

Following other studies (Weaver et al. 1999; Aguilera et al. 2007), we assume that CEP depends on a combination of external pressures (economic freedom in our context) and factors internal to the company. We extend previous studies as we postulate that the CEP is influenced by the interaction between internal motivations and economic freedom. More specifically, we assume that the interaction between economic freedom and internal motivations stimulates the participation in environmental networks that improves environmental outcomes at company level (see Fig. 1). Below, we will first discuss Hypothesis 1. Next, we elaborate on Hypothesis 2 which concerns the main contribution of this paper. 


\subsection{Participation in Environmental Networks and Environmental Outcomes}

In the small business context, a growing literature and awareness has emerged on the effectiveness of implicit and embedded approaches to environmental responsibility (Wickert et al. 2016). Effective implementation for SMEs requires cooperation, in which firms draw on their social capital and connections to stakeholders with high proximity (Wickert et al. 2016). External knowledge compensates the constrained in-house expertise and provides appropriate solutions to ecological challenges (Bos-Brouwers 2010). Participation in external networks to share best practices is particularly appropriate for this purpose (Valentine 2016). Indeed, small businesses that invest in tools and solutions with significant proenvironmental impact identify these solutions through other participants in their networks (Wohlfarth et al. 2017).

Based on this argument, we expect that participation in external environmental networks helps SMEs improving their environmental outcomes:

Hypothesis 1 Participation in environmental networks improves environmental outcomes.

\subsection{Economic Freedom, Internal Motivations and Participation in Environmental Networks}

Institutional theory describes how corporations' decisions depend on the institutional context (North 1990), and this framework is central to most studies considering differences in firms' corporate environmental performance across countries (Matten and Moon 2008; Ioannou and Serafeim 2012). But how the free market system affects the corporate environmental performance of companies is still an underdeveloped research theme. The degree of freedom of a market system can be measured by the economic freedom of a country, which refers to the personal liberty to voluntary exchange and compete in the market while enjoying security and property protection (Gwartney and Lawson 2003). Economic freedom comprises several dimensions such as low share of government in GDP and low tax rates, protection of property rights, freedom to exchange goods and services internationally, and no regulatory restraints that limit the freedom of exchange in credit, labor, and product markets. Earlier studies by Baughn et al. (2007) and Hartmann and Uhlenbruck (2015) find that economic freedom stimulates CEP.

However, when researchers only focus on institutional factors, there is insufficient consideration for differences in CEP at the individual company level. Although some companies have incorporated CEP in their business model, it is not standard business practice. There is a flavor of social desirability in the belief that alleviating regulatory constrains from firms increases their contribution to society and the environment in terms of resources and efforts. But corporations have more options. Various authors argue that capitalism may inhibit rather than encourage improving environmental performance, since private industry will mostly invest in technologies that it expects to be profitable (Bell 2015).

In this paper, we postulate that internal motivations of managers are fundamental for the company's engagement in CEP in a free market system. Motivation (i.e. the reason upon which one acts) is an important antecedent to behavior (Treviño et al. 2006). The literature on motives for CSP and CEP distinguishes between extrinsic and intrinsic motives (Muller and Kolk 2010; Rode et al. 2015; Abatayo and Lynham 2016). An extrinsic motive encourages CEP because of its instrumental value for other goals, such as financial performance 
or the company's reputation. Intrinsically motivated CEP requires no separate reward but the behavior itself (Vollan 2008). Intrinsic motivation may stem from personal satisfaction of engaging in CEP when executives enjoy helping others (Rabin 1998) or enjoy a 'warm glow' from contributing to a public good. But intrinsic motivation may also stem from a genuine concern for the environment and a sense of obligation to contribute to society and the welfare of future generations (Lindenberg 2001). The goal is then to act appropriately. Managers feel that they are responsible to prevent negative impacts of their companies on the natural environment (Bansal and Roth 2000).

We expect that economic freedom will hardly encourage companies to increase their engagement in CEP if they are not intrinsically motivated to take responsibility for the environment. That is, we expect that the positive relationship between economic freedom and CEP is conditional on intrinsic environmental motivation. Since environmental policies may require costly investments, companies will be less motivated by the extrinsic profit motive to make investments in CEP. ${ }^{2}$ This particularly holds for small and medium sized enterprises. The level playing field on which most SMEs operate means that they face severe competition and this puts profitability under pressure. Time, finances and a lack of skills and knowledge are commonly identified by SMEs as constraints to CEP (Studer et al. 2006). Low profitability induces low cost strategies and reduces a long-term orientation so that long-term strategic benefits from corporate environmental performance in terms of improved reputation, cost reduction, increased consumer demand and reduction in risks often remain beyond the strategic horizon. Moreover, because of their smaller size, Brammer et al. (2012) argue that SMEs are less visible to NGOs and media, compared to large companies, and cannot take advantage of CEP as instrumental for extrinsic profit motives. This implies that, as Lynch-Wood and Williamson (2007) argue, the profit motive is potentially weak to induce SMEs to go beyond compliance to the law, though we do not want to fully exclude reputational effects, e.g. if their CEP is monitored by local NGOs or local media. If a local NGO or newspaper spreads negative news about a small company, it might directly harm its reputation at its location (Jamali and Mirshak 2007) and the company would run the risk of economic loss (Russo and Tencati 2009). Because of their intimate relationship with the community in which they operate, SMEs also need to pursue a community-friendly policy (Jenkins 2009). Hence, also some SMEs will realize that low environmental performance may have serious consequences for the enterprise's reputation and economic performance and be extrinsically motivated to implement environmental policies in order to improve their environmental outcomes. However, if companies are motivated by the business case, they will adopt CEP only insofar it can be aligned to narrow strategic interests (Marens 2008). These companies will be tempted to use ceremonial instead of substantive CEP policies in order to gain social legitimacy without incurring the costs of substantive CEP policies. CEP is ceremonial if companies decouple policies from implementation and/or impacts (Jamali 2010; Okhmatovskiy and David 2012).

But if the management of a company is intrinsically motivated to improve environmental performance, economic freedom enables the managers to implement environmental policies that improve environmental outcomes, such as participation in environmental networks, even if these are costly and not profitable. Indeed, firms whose managers are highly intrinsically motivated to CEP are likely to apply broad and effective programmes if external conditions allow them to (Muller and Kolk 2010). If companies have little freedom to determine their

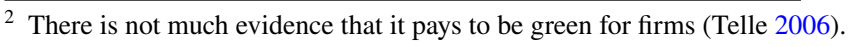


own policies, internal motivations will have a lesser effect on environmental performance. Under these conditions internally motivated companies would perhaps have a stronger inclination to do so, but in practice focus on complying with the interventions and standards prescribed by the government (Jackson and Apostolakou 2010).

The discussion above illustrates that in free market economies companies without intrinsic motivation are unlikely to participate in environmental networks that improve environmental outcomes, whereas intrinsic motivation is unlikely to stimulate participation in environmental networks if the economic freedom to undertake private initiatives is limited. In this interactive view, there must be a 'fit' between the institutional environment and firm-internal characteristics, including managers' intentions. Based on these arguments, we propose the following hypothesis.

Hypothesis 2 The participation in environmental networks is positively related to the interaction between the internal factor intrinsic environmental motivation and the external factor economic freedom

We complement the above hypothesis with a Placebo or falsification test, as follows. We compare intrinsic and extrinsic environmental motivation. Both motivational factors are significantly positively correlated (Table 2 ). Whereas from a theory point of view extrinsic motivation should have no or a small positive marginal effect on firms' participation in environmental networks, if our findings are e.g. based on an omitted variable correlated to motivation, we a priori expect both motivational terms to be equally affected. Thus, if we find a much smaller or no effect of extrinsic motivation, such finding would provide additional support for causality for the association mentioned in the second hypothesis.

Placebo test The participation in environmental networks is not (or much less) related to the interaction between extrinsic environmental motivation and economic freedom.

\section{Methods}

\subsection{Model Specification}

Taking the two hypotheses together, we formulate these as an empirical structural equation model (SEM):

$$
\begin{aligned}
P_{c, i}=\alpha_{P}+\beta_{I} F_{c} I_{i}+\beta_{E} F_{c} E_{i}+\gamma_{P} F_{c}+\delta_{I} I_{i}+\delta_{E} E_{i}+\chi_{P} X_{c}+\theta_{P} Y_{i}+\xi_{P} Z_{c, i}+\mu_{P, c, i} \\
O_{c, i}=\alpha_{O}+\varepsilon_{O} P_{c, i}+\beta_{O I} F_{c} I_{i}+\beta_{O E} F_{c} E_{i}+\gamma_{O} F_{c}+\delta_{O I} I_{i}+\delta_{O E} E_{i} \\
\quad+\chi_{O} X_{c}+\theta_{O} Y_{i}+\xi_{O} Z_{c, i}+\mu_{O, c, i}
\end{aligned}
$$

where $P_{c, i}$ and $O_{c, i}$ are the participation in environmental networks and outcomes of company $i$ in country $c$, respectively, $F_{c}$ is economic freedom, $I_{i}$ and $E_{i}$ are intrinsic and extrinsic motivations, $X_{c}$ are country control variables, $Y_{i}$ are company control variables, $Z_{c, i}$ are other control variables discussed below, and $\mu_{c, i}$ is white noise. Interaction is tested by the significance of the interaction terms $F_{c} I_{i}(\mathrm{H} 2)$ and $F_{c} E_{i}$ (Placebo) $\left(\beta_{I}\right.$ and/or $\left.\beta_{E}\right)$. In order to test for the interaction effects, we need to control for the linear effects of economic freedom and internal motivations and other controls in Eq. (1). The indirect effect of the interaction terms on environmental outcomes is tested by the significance of $\varepsilon_{O}$ in Eq. (2), while 
controlling for the direct effects of the interaction terms on environmental outcomes (Baron and Kenny 1986) and other controls.

We are mostly interested in the effect of an institutional macro variable, economic freedom, on the firm-level CEP, so that we can use cross-firm data with no problem of reverse causality.

\subsection{Data Sources}

We use the average score of the 'Economic Freedom of the World' index of Fraser Institute during 2008-2010, downloaded from the websites of Fraser Institute. Most statistical and other information underlying this index are received from government sources and are verified with independent, credible third-party sources.

Data for CEP was generated through a large online survey in 2011 that targeted small and medium sized enterprises (SMEs) operating in 12 countries from different European regions: Continental Western Europe (Austria, Germany, France, and the Netherlands); Scandinavia (Finland, Sweden, and Denmark); Mediterranean Europe (Italy, Spain); Central Europe (Poland and Hungary); and Anglo-Saxon Europe (the United Kingdom). This sample of countries is considered representative of the existing variety of political and economic systems in Europe. Before sending out the survey, we discussed the survey questions in two rounds with a group of 14 experts in CSP from the twelve European countries where the survey would be set out. The survey was also discussed with a CEP consultant for SMEs to test whether the survey fits the SME context. Next, we pre-tested it by interviewing executives from ten companies in different sectors. The aim of the interviews was to explore measures and terms to be used in order to secure content validity. Executives were asked to fill in the survey before the interview was held. Then the researchers visited the company and discussed the company's responses in depth to check the clarity of the survey questions and whether they suited the CEP of the company. Once agreed, the survey questions were translated from English into the national languages by 12 native speaker experts in the research team.

The response percentage of the companies that were invited to participate $(365,002$ companies in total) was $3.7 \%$, a reasonable figure considering the survey was electronic and required substantial effort to complete. This discourages participation, particularly for SMEs. 4338 companies filled in all questions used in this article, of which $91 \%$ are small and medium sized enterprises.

\subsection{Measures}

Following literature (Treviño et al. 2006; Lindenberg 2001; Muller and Kolk 2010) motivation is defined as the reason upon which one acts. A motive is assumed to have a causal effect on behavior (besides other causes). One way to empirically measure motives is by asking people for the reason for a certain action (Elster 2007). The principle of nemo gratis mendax (no one lies freely) suggests that expressions of motive should not be doubted per se, but only if there is reason because of particular circumstances (O'Mahoney 2012). Systematic errors can arise when respondents tend to report socially desirable answers or consciously or unconsciously aim for consistency between answers. In order to prevent social desirable answers, we followed several precautionary measures and ex-post tests recommended by Podsakoff et al. (2003). First, in the cover letter to the respondents, we emphasize confidentiality, reducing motives for a more favorable picture. Second, we separated 
questions on internal motivations in (questions 23-27), from those on environmental policies (questions 45-48), and those on environmental outcomes (questions 102-105), so that no connection between these questions is perceived. We measure intrinsic motivation by two survey questions. The first question measures moral motivation by asking the respondent to state his or her view on the extent to which the company's engagement in CEP is motivated by the company's responsibility for the environment and society. The second survey question measures personal satisfaction by inquiring to what extent personal satisfaction of the people in the enterprise is a motive to engage in environmental responsibility. Extrinsic motivation was measured by three survey questions on long-term financial benefits, reduction in reputational risks and customer demand as motives for engaging in CEP (see also Table 1 below). All survey questions are measured by a seven-point Likert scale.

The questions for participation in environmental networks were based on literature and in collaboration with the SME consultant. In response to the question 'Which measures are realized in your enterprise?', several measures were given, including participation in CEP networks in the supply chain (Pirsch et al. 2006; Bos-Brouwers 2010), partnerships with professional training institutes in order to anticipate the technological evolution of products or services (Bos-Brouwers 2010), participation in local CEP initiatives of governments or social organizations (Barth and Wolff 2009), and dialogue with societal organizations and local communities (Hall et al. 2015). For each measure, the respondent could choose between three options: 'no' (0), 'yes' (1) and 'unfamiliar with this measure.' The third option is recoded as 'no'.

Environmental outcomes was measured by self-reported outcome variables. Empirical studies on environmental performance often use ratings from professional rating bureaus (ASSET 4, etc.) that measure large companies. Such ratings are not available for SMEs and so we developed our own measurements, using the following steps. First, we analyzed how environmental performances are measured by professional rating bureaus. We only considered generic measurements, not sector specific variables. We sought guidance from an SME consultant who specialized in advising SMEs on their environmental performance to establish the kind of indicators known to micro, small and medium-sized companies, indicators that they could look up relatively easily when filling out the survey questions. Based on this, we selected energy use, water use, and waste disposal. Based on a pilot survey among 10 companies, we fine-tuned the cut-off values of seven categories ranging from +3 to -3 , measuring the $\%$ decrease in energy consumption, water consumption and waste during 2007-2010: 1 . Decreased by more than 5\% (3); 2 . Decreased by 3-5\% (2); 3 . Decreased by $1-3 \%(1) ; 4$. Not changed very much (0); 5 . Increased by $1-3 \%(-1) ; 6$. Increased by $3-5 \%(-2) ; 7$. Increased by more than $5 \%(-3)$.

We use both explorative and confirmatory factor analysis to test the clustering of the survey variables in the four factors identified by our labels 'Intrinsic motivation,' 'Extrinsic motivation', 'Environmental networks,' and 'Environmental outcomes'. Recall that the proposed clustering is based on the literature and clearly related to the theoretical meaning of these variables, but there is no previous literature that establishes the relation between our expected factors (intrinsic motivation etc.) and the survey variables. It is then common practice to use an exploratory factor analysis to test our predictions about the factor decomposition of the survey questions. Explorative factor analysis is independent of the structural model, the factor elements are chosen purely on the basis of the subset of survey questions, and free of any a priori assumed relationships. The results of the explorative factor analysis reported in Table 1 provide support for the four factors. The KMO measure of sampling adequacy and the Bartlett's Test of sphericity support the use of factor analysis on the dataset. The Cronbach's alphas confirm that the four factors are internally consistent, as they meet 


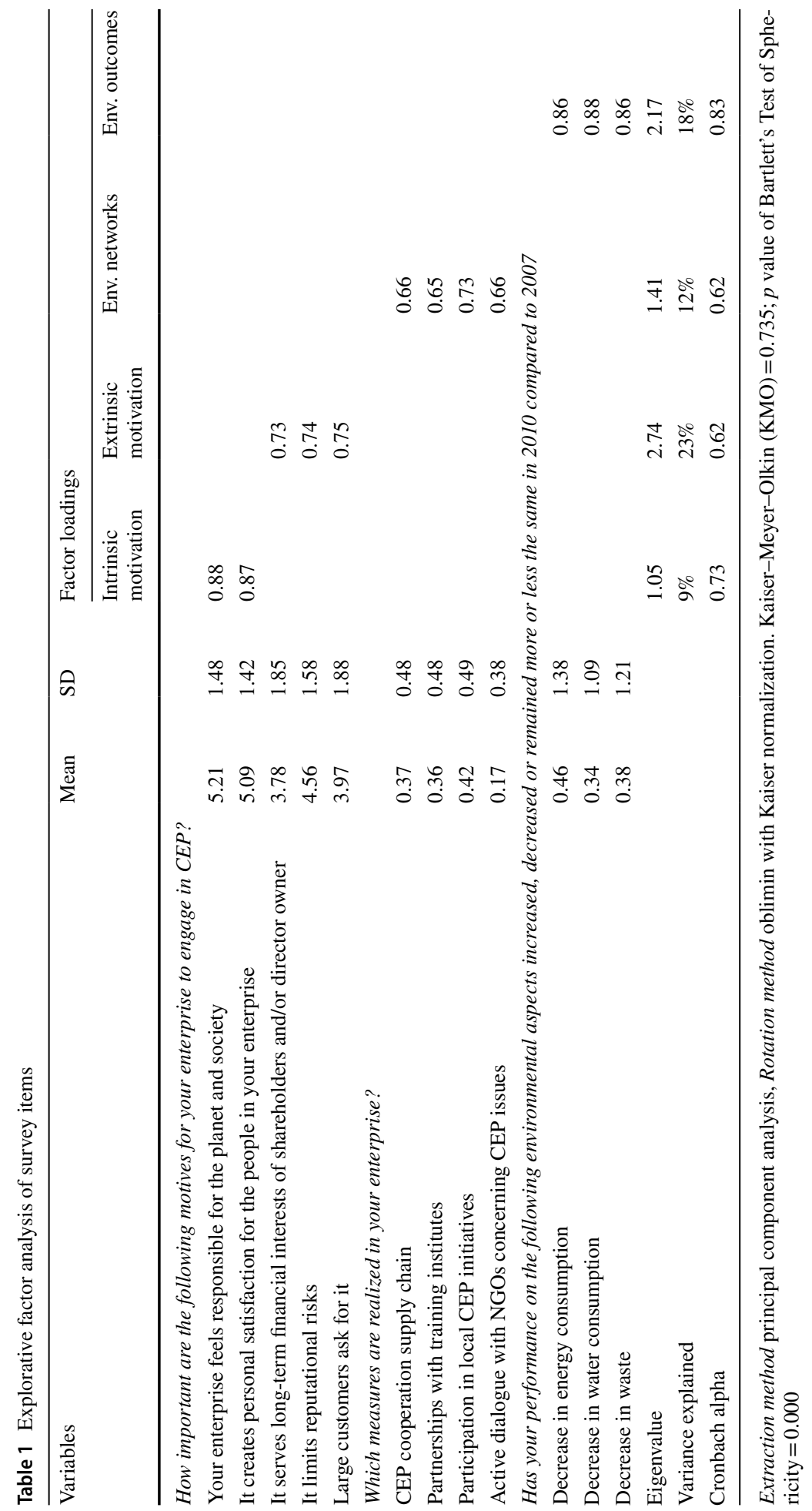


the accepted threshold of 0.60 . The confirmatory factor analysis tests validity of the factors in the specific context of the structural equation model. It is thus performed simultaneously with the estimation of the structural model that we present below (see Table 3 below).

\subsection{Control Variables}

We use four types of control variables (for measurement details, see footnotes of Table 2). At the macro level we controlled for GDP per capita (PPP, constant international USD in 2011), power distance, and individualism (Ioannou and Serafeim 2012). GDP per capita has been taken from World Bank and the indices for national culture from Hofstede (http:// geerthofstede.nl/dimensions-of-national-cultures). To control for the market environment in which the company operates we used sector fixed effects, the company's position in the chain, and intensity of price competition. Furthermore, we controlled for four firm-specific characteristics: the size and growth of the company (measured by the logarithm of the number of FTEs), the skill structure and the age structure of the company. Lastly, we controlled for the function (director-owner, director, manager, or other) and the age of the respondent.

\subsection{Reverse Causality and Non-response Bias}

Since economic freedom is measured at the country level and CEP at the level of the individual SME, there is no concern of reverse causality (from individual firms to countries) for Hypothesis 2. The direction of causality from network participation to environmental outcomes as stated in Hypothesis 1 is more difficult to establish statistically, however. Though the direction from network participation to environmental outcomes is more natural than its reverse, we believe, we have no statistical means to test its direction. Yet the most important feature of $\mathrm{H} 1$ is not its direction of causality, but its instrumental use in establishing that economic freedom interacted with internal motivation drives environmental outcomes. Thus, even if the coefficient $\varepsilon_{O}$ in Eq. (2) suffers from omitted variable bias or reverse causality, we will see in Table 3 that the coefficient $\beta_{O I}$ is significantly positive, and thus we establish also a direct effect of the interaction term on environmental outcomes. For the interpretation of that interaction term, the same argument applies as for Hypothesis 2, and thus the central theme of our study is robustly established.

In order to evaluate the non-response bias, we use Heckman's two-stage estimation procedure (Certo et al. 2016). The first step uses a logistic model that explains the response ( 0 for non-response; 1 for response). ${ }^{3}$ In the second step the ultimate model of interest is estimated. As exclusion restriction we used the degree of feeling European measured by the Eurobarometer (an annual survey of the European Commission based on approximately 1000 face-to-face interviews per country). Because the invitation letter that requested companies to respond to the survey was signed by a representative of the European Union, it is expected that respondents who feel more European are more inclined to cooperate to the survey, independent from their interest in CEP. The estimation results of the logistic model supported this proposition and showed a highly significant positive effect of feeling European on the response rate $(p<0.001)$, while controlling for sector, company size and the starting year of the company. From the regression result, we calculated the inverse Mills ratio, which indicates the degree that the response is influenced by unobserved characteristics of

\footnotetext{
3 We used the transformation proposed by Lee (1983) to transform probabilities into pseudo-probit scores for calculating the inverse Mill's ratio.
} 
Table 2 Data descriptives and correlations including control variables

\section{Mean SD Econ. freedom Intrinsic Extrinsic Env. networks Env. outcome} motivation motivation

\begin{tabular}{|c|c|c|c|c|c|c|c|}
\hline \multicolumn{8}{|c|}{ Country characteristics } \\
\hline Economic freedom & 7.33 & 0.24 & 1. & & & & \\
\hline Intrinsic motivation $^{\mathrm{a}}$ & 0.00 & 1.00 & 0.03 & 1. & & & \\
\hline $\begin{array}{l}\text { Extrinsic } \\
\text { motivation }^{\mathrm{a}}\end{array}$ & 0.00 & 1.00 & 0.08 & 0.56 & 1. & & \\
\hline Env. networks & 0.00 & 1.00 & 0.12 & 0.26 & 0.37 & 1. & \\
\hline Env. outcomes ${ }^{\mathrm{a}}$ & 0.00 & 1.00 & 0.04 & 0.05 & 0.06 & 0.09 & 1. \\
\hline \multicolumn{8}{|l|}{ Country controls } \\
\hline Power distance & 46.49 & 14.66 & -0.63 & -0.07 & -0.05 & -0.09 & -0.01 \\
\hline Individualism & 70.28 & 9.65 & 0.06 & -0.02 & 0.02 & -0.04 & -0.00 \\
\hline $\begin{array}{l}\text { GDP per capita } \\
\text { (natural log) }\end{array}$ & 3.16 & 0.43 & 0.57 & 0.03 & 0.05 & -0.01 & 0.00 \\
\hline \multicolumn{8}{|l|}{ Sector controls } \\
\hline Materials & 0.16 & 0.37 & -0.02 & -0.04 & -0.01 & -0.04 & 0.04 \\
\hline Energy & 0.03 & 0.18 & 0.00 & 0.02 & 0.05 & 0.05 & -0.01 \\
\hline Industrials & 0.17 & 0.37 & -0.03 & -0.02 & -0.01 & -0.02 & -0.03 \\
\hline Consumer staple & 0.04 & 0.19 & -0.01 & -0.02 & 0.02 & 0.02 & 0.01 \\
\hline $\begin{array}{l}\text { Consumer discre- } \\
\text { tionary }\end{array}$ & 0.17 & 0.38 & -0.04 & -0.01 & -0.01 & -0.02 & 0.01 \\
\hline Financials & 0.03 & 0.16 & 0.06 & -0.00 & 0.00 & 0.00 & 0.00 \\
\hline IT and com & 0.03 & 0.18 & 0.01 & 0.04 & -0.01 & -0.01 & -0.02 \\
\hline Other sectors & 0.37 & 0.51 & 0.06 & 0.04 & -0.02 & 0.04 & -0.01 \\
\hline \multicolumn{8}{|l|}{ Firm controls } \\
\hline $\mathrm{B} 2 \mathrm{C}^{\mathrm{b}}$ & 2.03 & 1.07 & -0.04 & 0.02 & 0.00 & 0.10 & -0.00 \\
\hline Price competition ${ }^{\mathrm{c}}$ & 5.07 & 1.88 & -0.19 & -0.03 & 0.01 & -0.09 & 0.01 \\
\hline Company size $^{\mathrm{d}}$ & 3.52 & 1.82 & 0.23 & 0.04 & 0.15 & 0.31 & 0.02 \\
\hline Company growth & 3.56 & 38.44 & 0.04 & 0.07 & 0.06 & 0.07 & -0.19 \\
\hline Young employees & 10.51 & 13.58 & 0.09 & 0.05 & 0.04 & 0.12 & -0.03 \\
\hline Medium aged $^{\mathrm{e}}$ & 67.26 & 22.80 & -0.21 & 0.00 & -0.00 & -0.07 & -0.03 \\
\hline Old aged ${ }^{\mathrm{e}}$ & 22.15 & 21.00 & 0.17 & -0.03 & -0.02 & -0.01 & 0.04 \\
\hline Low skilled ${ }^{\mathrm{f}}$ & 33.13 & 31.93 & 0.06 & -0.08 & -0.01 & -0.01 & 0.03 \\
\hline Medium skilled $^{\mathrm{f}}$ & 41.45 & 29.41 & -0.12 & -0.02 & 0.00 & -0.08 & -0.02 \\
\hline High skilled $^{\mathrm{f}}$ & 25.42 & 28.38 & 0.07 & 0.12 & 0.01 & 0.09 & -0.02 \\
\hline \multicolumn{8}{|l|}{ Respondent controls } \\
\hline Age respondent ${ }^{g}$ & 2.76 & 0.91 & 0.06 & 0.05 & -0.01 & -0.05 & 0.03 \\
\hline Owner & 0.33 & 0.47 & -0.05 & 0.04 & -0.07 & -0.14 & 0.01 \\
\hline Director & 0.19 & 0.39 & 0.12 & 0.04 & 0.02 & 0.07 & 0.01 \\
\hline Manager & 0.19 & 0.40 & 0.10 & -0.00 & 0.06 & 0.10 & 0.01 \\
\hline Other function & 0.29 & 0.45 & -0.14 & -0.08 & 0.01 & 0.01 & -0.03 \\
\hline
\end{tabular}

Italics: $p<0.05$; bold: $p<0.01$

${ }^{a}$ The constructed data for the factors intrinsic motivation, participation in environmental networks, and environmental performance are standardized to zero mean and unit standard deviation

${ }^{b}$ Mean response to 5 point scale ranging from: 'B2B'(1) to 'B2C'(5)

${ }^{\mathrm{C}}$ Mean response to 7 point scale ranging from: 'not at all'(1) to 'very much'(7)

${ }^{\mathrm{d}}$ Natural log, number of FTEs 
Table 2 (continued)

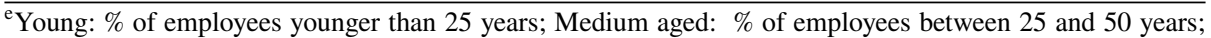
Old: $\%$ of employees older than 50 years

${ }^{\mathrm{f}}$ Low skilled: \% of employees with no qualifications, O-levels, CSEs, GCSEs; Medium skilled: \% of employees with A levels or BTEC equivalent; High skilled \% of employees with degree and post graduate level qualifications

${ }^{\mathrm{g}}$ Measured by four age groups $(1=<30 ; 2=30-45 ; 3=46-55 ; 4:>55$ years $)$

the company. ${ }^{4}$ We find that the inverse Mill's ratio is significantly related to intrinsic motivation and certifications. Based on these results, we decide to include the inverse Mill's ratio in the regression analysis, which removes the non-response bias part from the error terms.

\subsection{Common Method Bias}

In order to prevent common method bias in the measurement of internal motivations, environmental policies and outcomes, we followed several precautionary measures and ex-post tests recommended by Podsakoff et al. (2003). As a first precautionary measure, the scales for internal motivations and CEP questions differ, reducing commonalities in scale endpoints and anchoring effects. Second, as discussed above, we separated questions on internal motivations from those on environmental policies and outcomes, so that no connection between these questions is perceived. Third, we kept questions simple, specific and concise, steering respondents to least-effort genuine answers. Finally, we applied an ex post test for common method bias using the marker variable technique. The marker variable of our choice is theoretically unrelated to intrinsic motivation, and its correlation to motivation is an indicator of common source bias. As marker variable we selected the share of permanent contracts with employees (as a \% of all employee contracts) in 2010, for which we find a correlation of $0.005(p=0.746)$. This suggests that we do not need to correct the substantive survey variable outcomes for common source bias.

\section{Findings}

We used structural equation modeling (SEM) with maximum likelihood estimation for Eqs. (1) and (2). The structural paths and the confirmatory factor analysis ${ }^{5}$ are simultaneously estimated. As the economic freedom variables are country-level variables and CEP variables are firm-level variables, we cluster errors over countries to account for the unobservable factors that are correlated with firm's motivation and performance within each country and are not correlated with those from other countries (Peterson et al. 2012). Table 3 reports the estimation results for the structural paths. The results for control variables and measurement model (confirmatory factor analysis) are given in Table 7 in the "Appendix". The model is confirmed by global fit indices. The CFI and TLI indices suggest a good model fit (Kaplan 2009). Good model fit is also confirmed by the RMSEA measure, with value smaller than 0.06 (Hu and Bentler 1999).

\footnotetext{
4 The estimation results of the response model are reported in Table 6 in the "Appendix".

5 In formal notation, we have high-dimensional survey data $S_{c, i}$ for company $i$ in country $c$, and search for a 4-dimensional factor $F A C_{c, i}=\left(I_{c, i}, E_{c, i}, P_{c, i}, O_{c, i}\right)$ that minimizes the unexplained variation $\mu_{S, c, i}$.

$$
S_{c, i}=\alpha_{S}+\lambda_{S} F A C_{c, i}+\mu_{S, c, i}
$$
}

where $\lambda_{S}$ is called the loading matrix, presented in measurement part of Table 3 . 


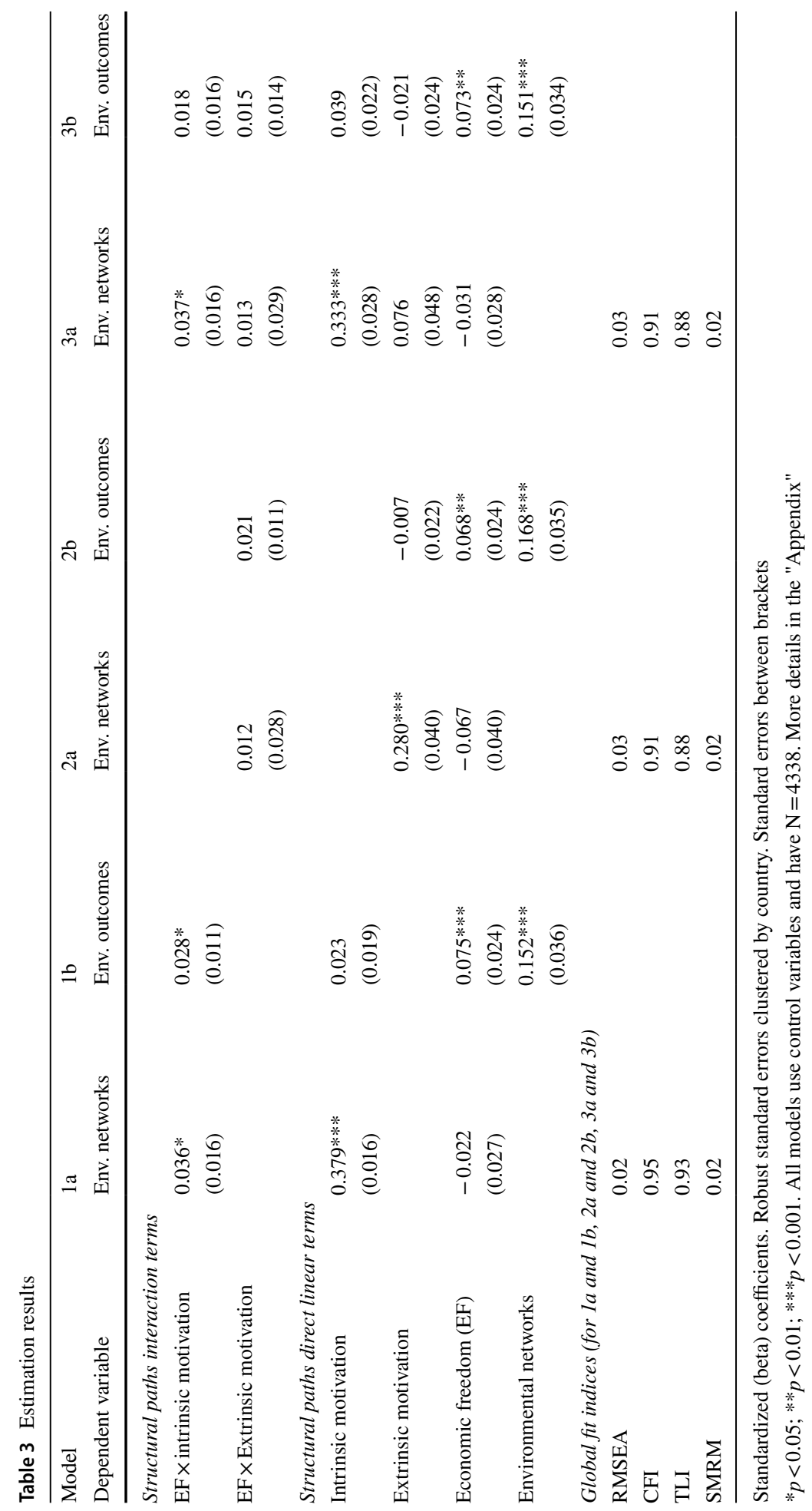


Table 4 Direct, indirect and total effects on environmental outcomes

\begin{tabular}{llll}
\hline & Direct effect & Indirect effect & Total effect \\
\hline Economic freedom (EF) & $\gamma_{O}=0.082(0.000)$ & $\gamma_{P} \varepsilon_{O}=-0.004(0.488)$ & $0.079(0.000)$ \\
Intrinsic motivation (I) & $\delta_{O I}=0.022(0.226)$ & $\delta_{I} \varepsilon_{O}=0.054(0.000)$ & $0.075(0.000)$ \\
$\mathrm{EF} \times \mathrm{I}$ & $\beta_{O I}=0.030(0.012)$ & $\beta_{I} \varepsilon_{O}=0.006(0.002)$ & $0.036(0.005)$ \\
\hline
\end{tabular}

Unstandardized coefficients

$p$ values between brackets

The estimation results in columns 1 and 2, model 1 , show that the interaction term of economic freedom and intrinsic motivation increases participation in environmental networks, in support of Hypothesis 2. The results in Columns 3 and 4 show no significant positive effect of the interaction term of economic freedom and extrinsic motivation, consistent with the placebo test. The last two columns show the effects to be robust, despite the correlation between the two internal motivation variables. The importance of intrinsic motivation vis-à-vis extrinsic motivation is further stressed by comparing the direct effects of intrinsic and extrinsic motivation on environmental networks. These seem highly significant when considered in isolation (columns 1-4), but the coefficient for extrinsic motivation suffers from omitted variable bias, shown in the last two columns. The joint model shows significant direct effects for intrinsic motivation and insignificant for extrinsic motivation. The last row shows that firms' participation in environmental networks have a significant positive effect on environmental outcomes, supporting Hypothesis 1.

From these estimation results we conclude that only the interaction between intrinsic motivation and economic freedom influences CEP. The global fit indices are best for the first model, so that columns 1 and 2 present our preferred model. Another noteworthy aspect of this model, anticipated in Sect. 3.5, is that the interaction term between economic freedom and intrinsic motivation is seen to have a direct, significant effect not only on company's participation in environmental networks but also on environmental outcomes ( $p$ value $=0.010$ ). This finding indicates that the interacting influence of intrinsic motivation and economic freedom on economic outcomes is not only mediated by cooperation in the supply chain, partnerships with training institutes, participation in local initiatives and dialogue with NGOs, but also by other measures that improve environmental outcomes, that are not included in our measurement of environmental networks. Loss of significance for this interaction effect in the last column we interpret as the result of collinearity between intrinsic and extrinsic motivation.

Based on the estimation results of model 1, we calculate the total effects of the interaction term of economic freedom and intrinsic motivation on environmental outcomes, that is, the sum of the direct effect and the indirect effects through participation in environmental networks $\left(\beta_{O I}+\beta_{I} \varepsilon_{O}\right)$. The results in Table 4 show that the direct, indirect as well as the total effect of the interaction term of economic freedom and intrinsic motivation on environmental outcomes are significant.

Next, we calculated the differential effects between Italy (lowest economic freedom) and the UK (highest economic freedom) for a firm with average, low and high intrinsic motivation. Table 5 shows that a rise in economic freedom induces companies with low intrinsic motivation to worsen environmental outcomes, whereas companies with high intrinsic motivation use the extra economic freedom for bettering their contribution to the environment. The table unambiguously shows the importance of the interaction between intrinsic 
Table 5 Estimated total effect of difference in economic freedom on environmental performance
Intrinsic motivation of companies $(\mathrm{X})$

\begin{tabular}{lll}
\hline$X=$ Lowest in sample & $X=$ Sample average & $X=$ Highest in sample \\
\hline-0.15 & 0.27 & 0.69
\end{tabular}

$\mathrm{a}_{1}\left(\mathrm{EF}_{\mathrm{UK}}-\mathrm{EF}_{\mathrm{It}}\right)+\mathrm{a}_{2}\left(\mathrm{EF}_{\mathrm{UK}}-\mathrm{EF}_{\mathrm{It}}\right) * \mathrm{X} . \mathrm{a}_{1}$ and $\mathrm{a}_{2}$ denote the total effects of economic freedom (EF) and the interaction term of economic freedom and intrinsic motivation, $\mathrm{EF}_{\mathrm{UK}}$ (standardized) economic freedom of $\mathrm{UK}, \mathrm{EF}_{\mathrm{It}}$ (standardized) economic freedom in Italy, and $\mathrm{X}$ (standardized) intrinsic motive

motivation and economic freedom for environmental outcomes. The average effect of economic freedom is positive, though.

\section{Conclusions}

\subsection{Contribution to Literature}

Small businesses are the most common business form globally, and they collectively account for up to $70 \%$ of industrial pollution worldwide (Hillary 2000). Governments may enforce improved environmental performance by government interventions, but these come with the disadvantage of losing out on voluntary initiatives. Though awareness of the need for a transition to a more sustainable economy is widely spread, not every firm is equally supportive for (voluntarily) measures that improve environmental performance. Particularly small and medium sized enterprises may be hesitant to invest resources in sustainable production processes, because of intensive competition. The question whether more or less economic freedom results in more environmental responsible management, has remained open. Previous research has shown that (certain aspects of) economic freedom might increase CSP (Baughn et al. 2007; Jackson and Apostolakou 2010; Ioannou and Serafeim 2012; Kinderman 2012; Hartmann and Uhlenbruck 2015). But these previous studies did not consider how the free market system affects the corporate environmental performance of companies. Although economic freedom may stimulate some companies to incorporate CEP in their business model, it is not a standard business practice.

We approached the question how economic freedom affects CEP by studying its interaction with internal motivations. For as far as we know, we are the first in the literature to consider this interaction mechanism. The main contribution of our analysis lies in the finding that the influence of economic freedom on environmental performance appears to be contingent on the intrinsic motivation of companies. This mechanism is reminiscent to interaction effects between external pressures and internal motivation proposed by Muller and Kolk (2010). They find that firm-internal characteristics, including managers' intentions, determine CSP benefits from external pressures. Also Weaver et al. (1999) find that firms whose managers are highly committed to ethics have broader and more deeply rooted ethics programs compared to firms engaged in response to external pressures. This indicates that intrinsic motivation increases the influence of external stimuli to perform certain types of behavior. We postulate that such interaction also regulates the influence of institutions on company's CEP, and our empirical results confirm the hypothesis: economic freedom stimulates firms whose managers are intrinsically motivated, to integrate 
environmental sustainability into their operations, while firms whose managers lack intrinsic motivation reduce their environmental performance.

Besides the interaction effect with intrinsic motivation, we also find a direct effect of economic freedom on environmental performance. With fewer government interventions, greater pressure may come from stakeholders towards the developing CEP practices (Jackson and Apostolakou 2010). Furthermore, economic freedom stimulates free trade, which increases the exchange of information and spurs managerial innovation and diffusion of new technologies that provide companies with more cost-efficient solutions to improve their environmental performance (Frankel and Rose 2005).

\subsection{Policy Implications and Future Research}

Our analysis illustrates a general idea that the success of free markets to solve environmental problems depends on the economic agents' motivations. Our results thereby provide an important complement to a simple theory in which profit-maximization is the preeminent rational objective; we find that non-financial motives play an important role in explaining outcome variables. Societies with free-market economies can flourish in-so-far as key market actors have positive intrinsic motivation and act virtuously. But our results cannot be read as an argument in favor of or against government regulation. As the case of climate change highlights, even if economic freedom improves the environmental performance of intrinsically motivated firms, such may be insufficient to reach a sustainable outcome. An obvious next step is to assess the connection between the two measures of external pressure, economic freedom and regulation, and their separate or interacting effects on CEP.

The lesson for management is that it is important to stimulate an ethical culture that encourages moral sensitivity and awareness. This has clear implications for recruitment policies and the socialization and training programs at the company level. At the institutional level, intrinsic motivation can be fostered by calls for social responsible behavior in important business publications and curricula in business schools, and by dialogues with unions, employees, community groups and other stakeholders; it appears that companies then better appreciate the concerns of these other actors (Campbell 2007).

Our study provides several opportunities for future research. First, a replication study would be useful to test robustness of our findings. In case of a reproductive survey, a potential target for improvement is the instrument used to predict the response rate. Our measure Feeling European is highly significant, but it is measured at country level, we cannot exclude that Feeling European is correlated directly to Environmental Outcomes, and the response-equation R2 remains low at 0.07. Second, the focus of this research is limited to small and medium-sized enterprises. This provides a good starting point setting for researching the interactions between institutions and intrinsic motivations, as the managers' values and motives play a relatively important role for this type of companies. But the selection also limits validity over the domain of large companies. The scope of our hypotheses would considerable be extended if our model can be tested to large companies as well. More theoretical and empirical research is necessary to elucidate the relationships between economic freedom, intrinsic motivations and CEP of large organizations.

Although our focus on SMEs has some major advantages - including that it provides a purer test on the effect of national institutions on CEP than research based on large, multinational companies operating in multiple countries and subject to the influence of multiple nation-level institutions - this focus comes at a cost. Because of the substantial effort 
required to obtain information on intrinsic CEP motives of SMEs, the sample of our study comprises a relatively small number of countries; we focused on Europe. Future research should aim to further test the robustness of the interaction of the influence of economic freedom and intrinsic motivation on CEP using a more extensive database, preferably considering a set of countries with a more diverse set of institutions.

Acknowledgements Johan Graafland has received a research Grant from Templeton World Charity Foundation, Inc. Templeton World Charity Foundation had no involvement in the study design; collection, analysis and interpretation of data; in the writing of the report; and in the decision to submit the article for publication.

\section{Compliance with Ethical Standards}

Conflict of interest The authors declare that they have no conflict of interest.

Open Access This article is distributed under the terms of the Creative Commons Attribution 4.0 International License (http://creativecommons.org/licenses/by/4.0/), which permits unrestricted use, distribution, and reproduction in any medium, provided you give appropriate credit to the original author(s) and the source, provide a link to the Creative Commons license, and indicate if changes were made.

\section{Appendix}

\section{See Tables 6 and 7.}

Table 6 Estimation results of logistic regression of survey response equation

\begin{tabular}{lc}
\hline & Beta \\
\hline Feeling European & $1.31^{* * * *}$ \\
Materials & $1.59^{* * *}$ \\
Energy & $1.33^{* *}$ \\
Industrials & $1.58^{* * *}$ \\
Consumer & $1.62^{* * *}$ \\
Utilities & $2.51^{* * *}$ \\
Financials & $1.52^{* * *}$ \\
IT and communication & $1.94^{* * *}$ \\
Company size $<10$ FTE & $-0.70^{* * *}$ \\
Company size 10-50 FTE & $-0.17 * *$ \\
Company size 50-250 FTE & $0.17 * * *$ \\
Age company & $0.04 *$ \\
$\mathrm{R}^{2}$ & 0.07 \\
\hline
\end{tabular}

The survey response is a binary variable ranging from 0 (no response to survey) to 1 (response to survey)

${ }^{*} p<0.05 ; * * p<0.01 ; * * * p<0.001$. The reference for sector and company size are other business and large companies. $\mathrm{N}=365,002$ 


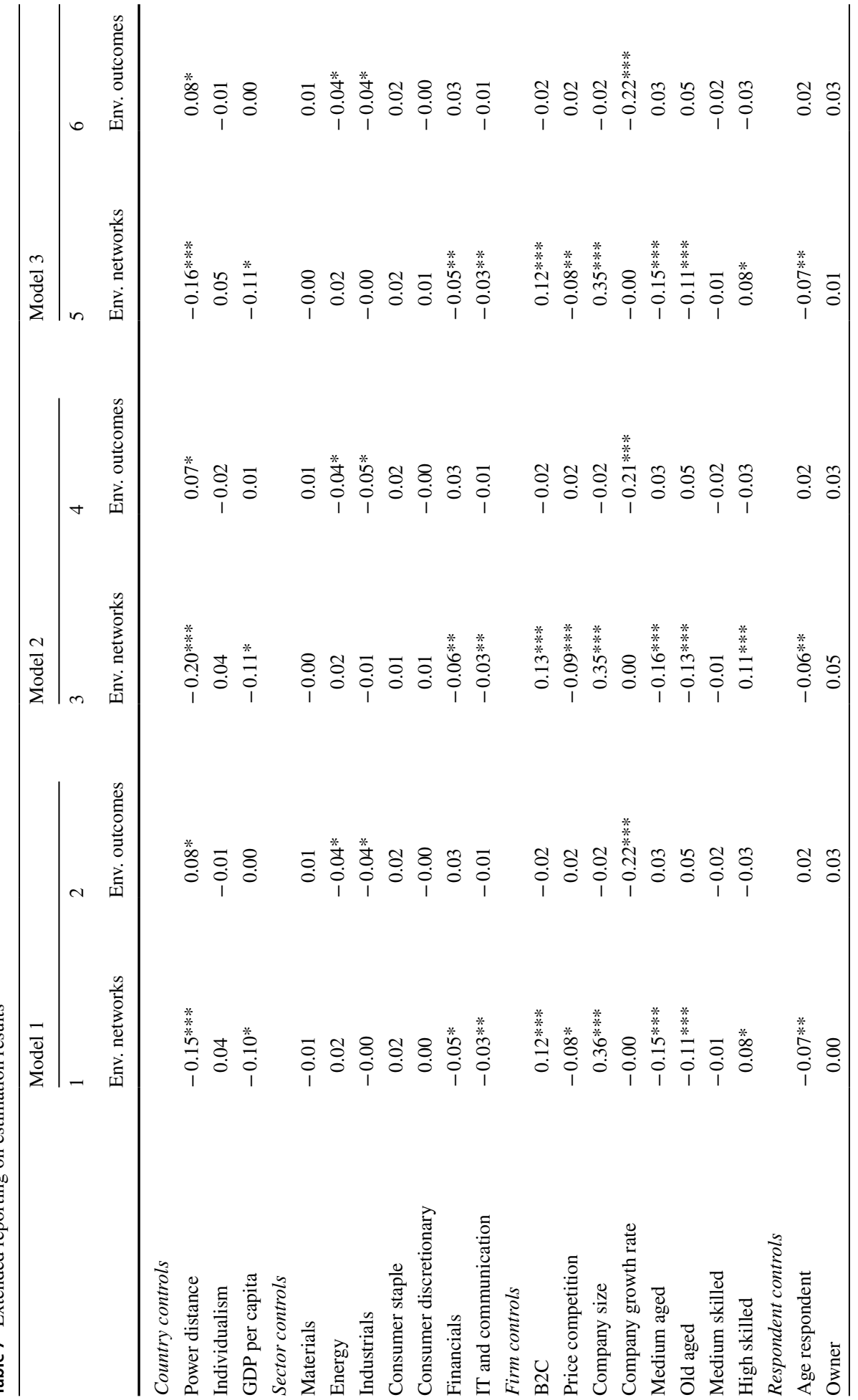




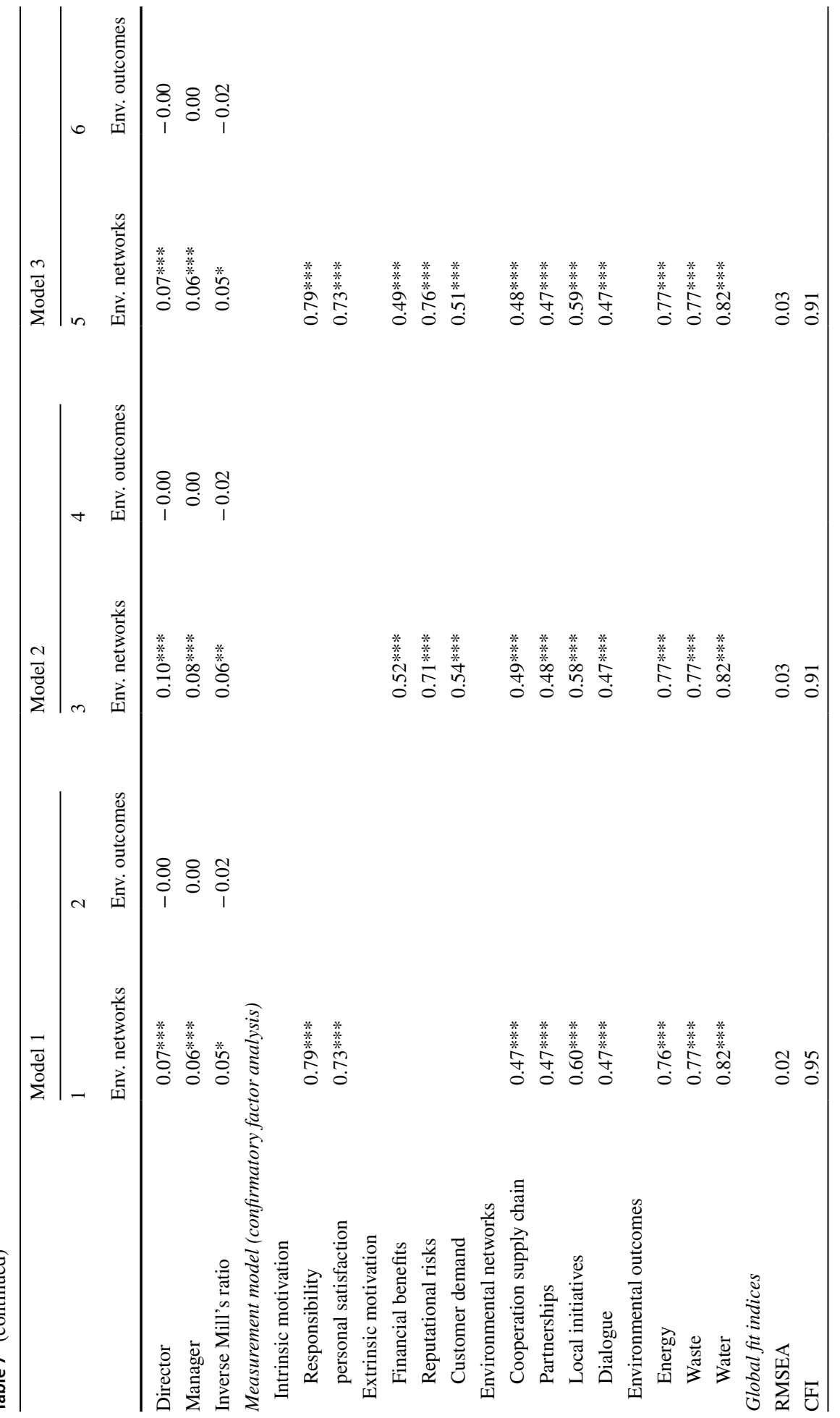




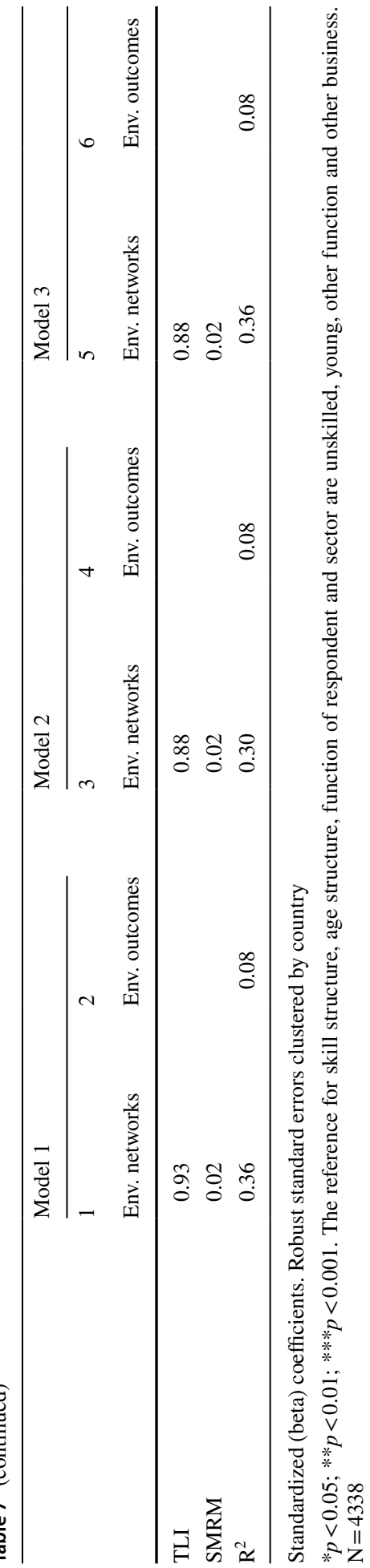




\section{References}

Abatayo AL, Lynham J (2016) Endogenous vs. exogenous regulations in the commons. J Environ Econ Manag 76:51-66

Agan Y, Acar MF, Borodin A (2013) Drivers of environmental processes and their impact on performance: a study of Turkish SMEs. J Clean Prod 51:23-33

Aguilera R, Rupp D, Williams C, Ganapathi J (2007) Putting the S back in corporate social responsibility: a multilevel theory of social change in organizations. Acad Manag Rev 32:836-863

Alberini A, Segerson K (2002) Assessing voluntary programs to improve environmental quality. Environ Resour Econ 22(1-2):157-184

Bansal P, Roth K (2000) Why companies go green: a model of ecological responsiveness. Acad Manag J 43(4):717-736

Baron RM, Kenny DA (1986) The moderator-mediator variable distinction in social psychological research: conceptual, strategic and statistical consideration. J Personal Soc Psychol 51:1173-1182

Barth R, Wolff F (2009) Corporate social responsibility in Europe: rhetoric and realities. Edward Elgar Publishing Ltd., Cheltenham

Baughn C, Bodie N, Mclntosh J (2007) Corporate social and environmental responsibility in Asian countries and other geographical regions. Corp Soc Responsib Environ Manag 14:189-205

Bell K (2015) Can the capitalist economic system deliver environmental justice? Environ Res Lett 10:125017

Bos-Brouwers H (2010) Corporate sustainability and innovation in SMEs: evidence of themes and activities in practice. Bus Strategy Environ 19:417-435

Bracke R, Verbeke T, Dejonckheere V (2008) What determines the decision to implement EMAS? A European firm level study. Environ Resour Econ 41(4):499-518

Brammer S, Hoejmose S, Marchant K (2012) Environmental management in SMEs in the UK: practices, pressures and perceived benefits. Bus Strategy Environ 21:423-434

Camisón C (2010) Effects of coercive regulation versus voluntary and cooperative auto-regulation on environmental adaptation and performance: empirical evidence in Spain. Eur Manag J 28(5):346-361

Campbell JL (2007) Why would corporations behave in socially responsible ways? An institutional theory of corporate social responsibility. Acad Manag Rev 32:946-967

Carson R (2010) The environmental Kuznets curve: seeking empirical regularity and theoretical structure. Rev Environ Econ Policy 4(1):3-23

Certo S, Busenbark J, Woo H, Semadeni M (2016) Sample selection bias and Heckman models in strategic management research. Strateg Manag J 37:2639-2657

Croson R, Treich N (2014) Behavioral environmental economics: promises and challenges. Environ Resour Econ 58(3):335-351

Daddi T, Testa F, Frey M (2016) Exploring the link between institutional pressures and environmental management systems effectiveness: an empirical study. J Environ Manage 183:647-656

Demirel P, Iatridis K, Kesidou E (2018) The impact of regulatory complexity upon self-regulation: evidence from the adoption and certification of environmental management systems. J Environ Manage 207:80-91

Elster J (2007) Explaining social behavior: more nuts and bolts for the social sciences. Cambridge University Press, Cambridge

Frankel JA, Rose AR (2005) Is trade good or bad for the environment? Sorting out the causality. Rev Econ Stat 87(1):85-91

Gwartney J, Lawson R (2003) The concept and measurement of economic freedom. Eur J Political Econ 19:405-430

Hall N, Lacey J, Carr-Cornish S, Dowd A (2015) Social licence to operate: understanding how a concept has been translated into practice in energy industries. J Clean Prod 86:301-310

Haller SA, Murphy L (2012) Corporate expenditure on environmental protection. Environ Resour Econ 51(2):277-296

Hartmann J, Uhlenbruck K (2015) National institutional antecedents to corporate environmental performance. J World Bus 50:729-741

Hillary R (2000) Small and medium-sized enterprises and the environment: business imperatives. Greenleaf, Sheffield

Hu LT, Bentler PM (1999) Cutoff criteria for fit indexes in covariance structure analysis: conventional criteria versus new alternatives. Struct Equ Model 6:1-55

Ioannou I, Serafeim G (2012) What drives corporate social performance? The role of nation-level institutions. J Int Bus Stud 43:834-864 
Jackson G, Apostolakou A (2010) Corporate social responsibility in Western Europe: an institutional mirror or substitute? J Bus Ethics 94:371-394

Jamali D (2010) MNCs and international accountability standards through an institutional lens: evidence of symbolic conformity or decoupling. J Bus Ethics 95:617-640

Jamali D, Mirshak R (2007) Corporate social responsibility (CSR): theory and practice in a developing country context. J Bus Ethics 72(3):243-262

Jenkins H (2009) A 'business opportunity' model of corporate social performance for small- and mediumsized enterprises. Bus ethics Eur Rev 18:21-36

Kaplan D (2009) Structural equation modeling: foundations and extensions, vol 10. Advanced quantitative techniques in the social sciences series. Sage Publications Inc., California

Kinderman D (2008) The political economy of corporate responsibility in Germany, 1995-2008. Mario Einaudi Center for International Studies Working Paper No. 5-08

Kinderman D (2012) Free us up so we can be responsible. The co-evolution of corporate social responsibility and neo-liberalism in the UK, 1977-2010. Soc Econ Rev 10:135-157

Lee L (1983) Generalized econometric models with selectivity. Econometrica 51:507-513

Lindenberg S (2001) Intrinsic motivation in a new light. Kyklos 54:317-342

Lynch-Wood G, Williamson D (2007) The social license as a form of regulation for small and medium enterprises. J Law Soc 34:321-341

Marens R (2008) Recovering the past: reviving the legacy of the early scholars of corporate social responsibility. J Manag Hist 14:55-72

Matten D, Moon J (2008) "Implicit" and "explicit" CER: a conceptual framework for a comparative understanding of corporate social responsibility. Acad Manag Rev 33(2):404-424

Muller A, Kolk A (2010) Extrinsic and intrinsic drivers of corporate social performance: evidence from foreign and domestic firms in Mexico. J Manage Stud 47:1-26

North D (1990) Institutions, institutional change and economic performance. Cambridge University Press, Cambridge

O'Mahoney J (2012) Why did you do that? A methodological exploration of motive attribution. http://ssrn. com/abstract=2108912. Accessed 3 Sept 2017

Okhmatovskiy I, David RJ (2012) Setting your own standards: internal corporate governance codes as a response to institutional pressure. Organ Sci 23:155-176

Pellerano JA, Price MK, Puller SL, Sánchez GE (2017) Do extrinsic incentives undermine social norms? Evidence from a field experiment in energy conservation. Environ Resour Econ 67(3):413-428

Peterson M, Arregle J, Martin X (2012) Multilevel models in international business research. J Int Bus Stud 43:451-457

Pirsch J, Gupta S, Landreth Grau S (2006) A framework for understanding corporate social responsibility programs as a continuum: an exploratory study. J Bus Ethics 70:125-140

Podsakoff PM, MacKenzie SB, Lee JY, Podsakoff NP (2003) Common method biases in behavioral research: a critical review of the literature and recommended remedies. J Appl Psychol 88(5):879-903

Rabin M (1998) Psychology and economics. J Econ Lit 36:11-46

Revell A, Stokes D, Chen H (2010) Small businesses and the environment: turning over a new leaf? Bus Strategy Environ 19:273-288

Rode J, Gómez-Baggethun E, Krause T (2015) Motivation crowding by economic incentives in conservation policy: a review of the empirical evidence. Ecol Econ 117:270-282

Russo A, Tencati A (2009) Formal vs informal strategies: evidence from Italian micro, small, medium-sized and large firms. J Bus Ethics 85(2):339-353

Studer S, Welford R, Hills P (2006) Engaging Hong Kong businesses in environmental change: drivers and barriers. Bus Strategy Environ 15:416-431

Telle K (2006) "It pays to be green"-a premature conclusion? Environ Resour Econ 35(3):195-220

Treviño LK, Weaver GR, Reynolds SJ (2006) Behavioral ethics in organizations: a review. J Manag 32:952-990

Valentine S (2016) Kalundborg symbiosis: fostering progressive innovation in environmental networks. J Clean Prod 118:65-77

Vollan B (2008) Socio-ecological explanations for crowding-out effects from economic field experiments in southern Africa. Ecol Econ 67:560-573

Weaver G, Treviño L, Cochran P (1999) Corporate ethics programs as control systems, Influences of executive commitment and environmental factors. Acad Manag J 42:41-57

Wickert C, Scherer AG, Spence LJ (2016) Walking and talking corporate social responsibility: implications of firm size and organizational cost. J Manage Stud 53(7):1169-1196

Williamson D, Lynch-Wood G, Ramsay J (2006) Drivers of environmental behaviour in manufacturing SMEs and the implications for CSR. J Bus Ethics 67:317-330 
Wohlfarth K, Eichhammer W, Schlomann B, Mielicke U (2017) Learning networks as an enabler for informed decisions to target energy-efficiency potentials in companies. J Clean Prod 163:118-127

Wood DJ (1991) Corporate social performance revisited. Acad Manag Rev 16(4):691-718

Wood D (2010) Measuring corporate social performance: a review. Int J Manag Rev 12(1):50-84

Publisher's Note Springer Nature remains neutral with regard to jurisdictional claims in published maps and institutional affiliations. 